\title{
A POLUIÇÃO POR PLÁSTICOS E A EDUCAÇÃO AMBIENTAL COMO FERRAMENTA DE SENSIBILIZAÇÃO
}

\author{
Thays Maria Queiroz Abreu Carneiro ${ }^{1}$ \\ Laís Araújo da Silva ${ }^{2}$ \\ Mariana Guenther ${ }^{3}$
}

Resumo: A poluição por plásticos é um dos maiores impactos ambientais da atualidade. Nesse artigo discutimos esse problema, desde a origem dos plásticos, seu consumo excessivo e o resultante acúmulo de resíduos, e apresentamos soluções práticas através de iniciativas de Educação Ambiental. Nesse contexto, apresentamos o projeto "Xô Plástico", uma iniciativa desenvolvida no estado de Pernambuco que vem promovendo sensibilização e mudanças de hábitos através de mutirões de limpeza de praias e manguezais. Através desse relato pretendemos sensibilizar também nossos leitores quanto a esse grave problema de poluição e estimular o desenvolvimento de mais iniciativas como essa em outras regiões do Brasil e do mundo.

Palavras-chave: Resíduos Sólidos; Poluição; Oceano; Praias; Manguezais.

Abstract: Plastic pollution is one of the greatest environmental impacts nowadays. In this article we discuss this problem, from the origin of plastics, their excessive consumption and the resulting waste accumulation, and we present practical solutions through Environmental Education initiatives. In this context, we present the project "Xô Plástico" ("Plastic, get away!"), an initiative developed in the state of Pernambuco that has been promoting awareness and changes in habits through joint efforts to clean beaches and mangroves. Through this report, we intend to raise our readers' awareness of this serious pollution problem and encourage the development of more initiatives like this in other regions of Brazil and around the world.

Keywords: Solid Wastes; Pollution; Ocean; Beaches; Mangroves.

\footnotetext{
${ }^{1}$ Graduanda em Ciências Biológicas, Universidade de Pernambuco.

2 Graduanda em Ciências Biológicas, Universidade de Pernambuco.

3 Professora Adjunta, Instituto de Ciências Biológicas, Universidade de Pernambuco.

E-mail: mariana.guenther@upe.br, Lattes: http://lattes.cnpq.br/6562095215127779
} 


\section{Introdução}

A poluição por plásticos pode ser considerada como um dos mais graves impactos ambientais da atualidade, afetando tanto os ambientes terrestres quanto os aquáticos. Os resíduos de plásticos descartados nas ruas e nas praias, acumulam-se nos rios e nos mares, formando verdadeiras ilhas de plástico. E como esse material não é biodegradável, ou seja, não é decomposto por microrganismos como os resíduos orgânicos, uma vez descartados, torna-se um gravíssimo problema ambiental (HARRIS et al., 2021; KURNIAWAN et al. 2021).

Imagens de tartarugas, aves marinhas, peixes, golfinhos e baleias sendo mortos por causa da ingestão de plásticos são comuns em todos os noticiários ao redor do mundo (DALY, 2018; GIBBENS, 2018; LEAHY, 2019). No final, todos os resíduos que nós descartamos de forma inadequada tem seu destino final nos oceanos. A "grande mancha de lixo do Pacífico" descrita pelo oceanógrafo Charles Moore em 1997 (http://www.captain-charlesmoore.org/trash-vortex), é uma região do oceano Pacífico, mais precisamente entre a California e o Havaí - o Giro Pacífico Norte, que acumula grande quantidade dos plásticos que chegam no oceano (MOORE et al., 2001; PARKER, 2018; NATGEO, 2019). Em 2018, pesquisadores estimaram que essa mancha se estendia por mais de 1,6 milhões de quilômetros quadrados, contendo por volta de 79.000 toneladas desse material (LEBRETON et al. 2018).

O objetivo desse artigo é discutir o problema do plástico, desde sua origem, consumo e descarte, e evidenciar a importância da Educação Ambiental como ferramenta de sensibilização cidadã e mudança de hábitos, trazendo como exemplo uma iniciativa que está sendo desenvolvida no estado de Pernambuco: o projeto de Educação Ambiental "Xô Plástico". Este projeto vem promovendo, através de ações de limpeza das praias, a sensibilização de banhistas, turistas, comerciantes, estudantes e todos aqueles que vêm se envolvendo nesses verdadeiros mutirões de limpeza. Através desse relato pretendemos promover a sensibilização dos leitores quanto a esse grave problema de poluição e estimular novas iniciativas como essa a se desenvolverem em outras regiões do Brasil e do mundo.

\section{A origem dos plásticos}

$\mathrm{Na}$ busca pela obtenção de novos materiais que substituíssem os de origem natural, como cascos e chifres de animais (que eram utilizados para a confecção de objetos como pentes, fivelas e botões) e alguns produtos de origem vegetal (como o âmbar, goma-laca e guta-percha), no início do século XX surgiu um novo tipo de material chamado plástico, que com algumas mudanças e adaptações passou a ser comercializado no mundo todo (DIEZ, 2009). Plástico é uma palavra que tem origem do grego, plastikós, que originalmente significava "flexível e facilmente moldada". Dessa forma, ele é 
um material sintético obtido por meio de fenômenos de polimerização (reação química que dá origem aos polímeros - longas cadeias moleculares) ou multiplicação artificial dos átomos de carbono nas correntes moleculares dos compostos orgânicos, derivados do petróleo ou de outras substâncias naturais (MIRANDA, 2010).

Desde 1862 este material vem tomando espaço no mundo. De início o inglês Alexander Parkes desenvolveu a "Parkesina" (como material substituto para a borracha, que era a matéria prima utilizada na época), que é um tipo de resina criada a partir da celulose, sendo bastante flexível, moldável quando aquecida e resistente à água. Porém devido a seu alto custo, não se obteve investimento (MIRANDA, 2010). Ainda em 1862, com o objetivo de substituir o marfim nas bolas de bilhar devido ao seu uso desenfreado causando uma ameaça aos elefantes, a empresa Pheland Collander lançou um concurso em Nova York (EUA), onde quem conseguisse encontrar um substituto para 0 marfim na confecção das bolas de bilhar ganharia dez mil dólares (MIRANDA, 2010). Então, o tipógrafo John Wesley Hyatt descobriu um material a base de celulose natural tratado com ácido nítrico e cânfora (LIMA; OKIMOTO, 2009), futuramente chamado de "celuloide". Esse material foi bastante utilizado na fabricação de brinquedos, tintas, vernizes e na fabricação de películas fotográficas e filmes. Entretanto ele apresentava uma alta inflamabilidade, trazendo sérios prejuízos à indústria cinematográfica (PIATTI; RODRIGUES, 2005). Mas foi somente em 1909 que o químico Leo Hendrik Baekeland descobre as resinas formol-fenólicas, a "baquelita", que foi o primeiro plástico totalmente sintético, duro, rígido e resistente ao calor após ser moldado, dando início a "Era dos Plásticos". A baquelita foi ainda bastante utilizada, sendo empregada durante a segunda guerra mundial na fabricação de moedas, na produção de algumas peças automotivas da Ford Motor Company, na fabricação de carcaças de equipamentos elétricos (como telefones), mas devido a razões estéticas por sua pouca variação de cores, ela foi substituída por outros polímeros (PINTO et al., 2012).

Em 1922, o químico alemão Hermann Staudinger comprovou que a borracha é uma macromolécula, composta por unidades moleculares repetidas e de grande tamanho. Esta comprovação trouxe a descoberta dos poliestirenos, das borrachas sintéticas, do vinil, das poliuretanas e silicones, sendo todos esses de obtidos de matérias-primas vegetais e minerais. Estimase que no fim dos anos 20 e início dos anos 30, foram produzidas cerca de 23.000 toneladas de plástico, nos EUA. Foi em 1929 que se iniciou a produção de vinylite, um copolímero de cloreto de vinila utilizado na fabricação dos discos da gravadora RCA Victor. O material responsável pela fabricação dos discos fonográficos era a goma-laca (advinda dos ramos e galhos de diversas espécies de árvores da Índia), que foi usado até 1952, onde foi substituído pelo PCV (policloreto de vinila) dando origem ao de disco de vinil. A partir de 1936 os tubos de PVC começaram a ser utilizados no fornecimento de água residencial e despejo esgoto doméstico (MIRANDA, 2010). 
A primeira fibra têxtil sintética totalmente sintética, o nylon (poliamida), foi desenvolvida e patenteada (1937) pelo Grupo de Química da Du Pont (EUA). Com este material pôde-se fabricar velcro, meias femininas, roupas íntimas, roupas de banho, bermudas e roupas esportivas. A partir de 1945, o plástico já estava presente nas residências de milhares de pessoas, independente de condição social. Materiais como vidro, madeira, algodão, celulose, metais, couro, que eram matérias-primas utilizadas pelo homem há milhares de anos foram substituídas por um produto que possibilitou o acesso a bens de consumo a pessoas de baixa renda (CORTEZ, 2016).

A produção de plástico virgem aumentou em 200 vezes desde 1950, e cresce a um índice de 4\% ao ano desde 2000 (GEYER et al., 2017). Um exemplo claro deste crescimento são as sacolas plásticas. Historicamente, a inserção e crescimento das sacolas plásticas no mercado, substituindo as tradicionais embalagens de papel, teve início na década de 70. Essa substituição veio mediante a problemática do desmatamento, que trouxe bastante repercussão e destaque nos eventos que discutiam o meio ambiente na época. Porém, com a vinda das sacolas plásticas e suas diversas atribuições, podendo-se destacar sua leveza, baixo custo, estabilidade sob calor, transparência, flexibilidade, assepsia e capacidade de suportar peso sem romper-se, outras questões foram sendo levantadas e discutidas (SANTOS et al., 2012).

Devido a sua versatilidade, durabilidade, estética, maleabilidade, e, principalmente, a sua acessibilidade econômica, ele provocou mudanças no consumo e consequentemente no estilo de vida das pessoas. A possibilidade de confecção de diversos artigos e objetos com o custo reduzido é um dos principais motivos para a sua grande disseminação (PIATTI; RODRIGUES, 2005)

\section{O consumo dos plásticos e a geração de resíduos}

Entre as décadas de 1950 e 1960 a indústria do plástico cresceu notavelmente. Ele tem sido o material mais usado no mundo desde 1976 e foi considerado uma das maiores invenções do século passado, por serem bens de consumo baratos o suficiente em que todas as camadas da sociedade tinham acesso, o que ficou conhecido como "democratização das coisas" (MIRANDA, 2010). O plástico se tornou onipresente no meio ambiente criando assim um grande desafio para o planeta, sociedade e a economia global. Os solos, águas doces e oceanos estão contaminados pela sua presença. Se tratando dos oceanos, a poluição plástica pode chegar a 300 milhões de toneladas métricas até 2030 , considerando as atuais projeções de crescimento populacional, projeções de PIB per capita, e na atual geração de resíduos plásticos (GEYER et al., 2017).

Com a sua popularização e confecção exacerbada no século XIX, grande parte desse produto, principalmente as embalagens, é produzido e 
descartado no primeiro uso, gerando assim uma enorme quantidade de lixo e causando desequilíbrio em diversos ecossistemas. Um problema que vem desde o consumidor e passa pelos diversos setores da sociedade, além da falha na legislação, regulamentações e gestão a de resíduos sólidos. As falhas sistemáticas ao longo da cadeia comercial do plástico fazem com que o descarte do plástico na natureza seja mais barato que o manejo eficaz até o fim de seu ciclo de vida.

Contudo, não podemos esquecer que existem os impactos negativos relacionados à sua vida útil e baixa degradabilidade, podendo demorar de 100 a 400 anos para degradar-se no meio ambiente pela ação de raios ultravioletas, umidade e calor (SANTOS et al., 2012). Além disso, problemas como poluição visual devido à disposição dos resíduos nas ruas, parques, praças e ambientes turísticos, o entupimento das vias públicas de drenagem e os alagamentos em épocas de fortes chuvas, e o aumento da população de mosquitos transmissores de doenças como malária, dengue, Zika e Chikungunya, são resultado da má gestão e destinação desses resíduos (SOBRAL; SOBRAL, 2019).

No ambiente marinho, o lixo plástico pode ser carregado por milhares de quilômetros pelas correntes oceânicas, afetando a vida de tartarugas, pássaros, mamíferos marinhos, corais, assim como uma variedade de peixes e crustáceos, sendo um dos importantes problemas ambientais marinhos globais do século XXI (SANTOS et al., 2012).

Desde 2000 o mundo já produziu a mesma quantidade de plástico que em todos os anos anteriores somados. A produção cresceu rapidamente neste século devido ao baixo custo, versatilidade e confiabilidade do material. Entretanto, esse consumo e produção demasiada do plástico tornou-se o maior problema do século, visto que mais de $75 \%$ de todo plástico já produzido já virou lixo (WIT et al, 2019). Devido à má gestão dos resíduos, estima-se que um terço de todo o plástico descartado tenha se inserido na natureza como poluição terrestre, de água doce ou marinha (PIATTI; RODRIGUES, 2005). Acredita-se que a maior parte desses resíduos mal administrados veio a poluir ecossistemas terrestres, e que $80 \%$ do plástico nos oceanos seja proveniente da poluição terrestre (LI et al., 2016). A poluição por plásticos mata a vida selvagem e danifica os ecossistemas naturais (UNEP, 2016).

Mais de 240 espécies diferentes de animais já ingeriram plástico em sua dieta. Como esses animais não conseguem digeri-lo, sua ingestão resulta em abrasões internas ou obstruções do aparelho digestivo e até a morte (HARDING, 2016). O enredamento também é uma problemática para a fauna marinha. Estima-se que no mínimo mil tartarugas marinhas morram todos os anos devido ao enredamento em resíduos plásticos, o que inclui equipamentos de pesca perdidos ou descartados (DUNCAN et al., 2017). Já os impactos diretos pela ingestão do plástico à saúde humana ainda são desconhecidos. Pessoas podem ingerir plásticos através do consumo de alimentos contaminados com micro e nano plásticos, como o sal de cozinha, sendo a 
maior probabilidade através de frutos do mar, especialmente mariscos, mexilhões e ostras (FAO, 2014). Segundo um estudo de Wit e colaboradores (2019), mais de 104 milhões de toneladas de plástico irão poluir nossos ecossistemas até 2030 se nenhuma mudança acontecer na nossa relação com o material.

Estudos organizados pela Agência de Conservação Oceânica indicam que as sacolas plásticas representam $5,4 \%$ do lixo coletado, são o oitavo item mais comum encontrado e é o primeiro da lista dentre os resíduos perigosos. (SANTOS et al., 2012). As características do material das sacolas plásticas, e a maneira como as usamos, amplia as preocupações com seu consumo, já que foram projetadas para serem usadas uma vez e depois descartadas (EPHC, 2008). Este descaso com o uso das sacolas plásticas, assim como copos, garrafas e demais embalagens, só agrava a situação local e globalmente, tornando-se um desafio para a gestão de resíduos sólidos e para o meio ambiente.

Outro grande protagonista desta problemática é o copo plástico descartável. Em um país que produz anualmente 100 mil toneladas de copos plásticos e não recicla nem $10 \%$ deste material, ele torna-se um vilão potencial, visto que seu tempo de uso é de aproximadamente 13 segundos. Por ser o resíduo sólido menos reciclado ao redor do planeta e possuir baixo custo de mercado, ele não é tão valorizado no quesito reciclagem, onde empresas de cooperativas chegam a pagar $R \$ 0,20$ pelo $\mathrm{kg}$ do copo, o que equivale a aproximadamente 300 unidades (RODRIGUES, 2020).

A falta de reciclagem deste material junto com seu descarte incorreto faz com que este resíduo acabe nos oceanos, fazendo parte de $80 \%$ de lixo plástico encontrado nos mares, segundo a ONU. Mas o impacto dos copos descartáveis vem bem antes do pós-uso. Na sua produção são gastos de 500 $\mathrm{ml}$ a 3 litros de água por unidade, sendo um volume 10 vezes maior do que lavar o mesmo copo após a sua utilização, também 8 gramas de poliestireno (PS) ou polipropileno (PP) e $6 \mathrm{Wh}$ de energia elétrica são utilizados. Além disso, a produção provoca uma considerável emissão de gás carbônico $\left(\mathrm{CO}_{2}\right)$, dentre outros responsáveis pelo desequilíbrio do efeito estufa, uma das formas de contribuição para o aquecimento do planeta (QUIRINO; SANTOS, 2020). Entretanto, os copos descartáveis somente deixarão de ser um desafio constante para a natureza quando houver mudança no comportamento de quem consome o produto, da consciência acerca dos impactos e das limitações de destinação e reciclagem do material.

A produção dos plásticos e seu consumo desenfreado e insustentável estão gerando resíduos mais rapidamente do que sua capacidade de serem tratados pela gestão de resíduo de cada país, causando uma preocupação urgente e global diante do aumento da poluição e da impossibilidade de tratamento adequado em uma unidade regulamentada. Os resíduos plásticos mal administrados são aqueles deixados sem coleta, despejados abertamente na natureza, nas cidades ou tratados em aterros não 
regulamentados. Acredita-se que a maior parte desses resíduos plásticos mal administrados, equivalente a $90 \%$, poluiu a natureza em terra, como o solo e corpos de água potável, e os outros 10\% cheguem aos oceanos (JAMBECK et al., 2015), resultando em diversos impactos.

\section{A Educação Ambiental como ferramenta de sensibilização e promoção de mudança de hábitos}

Através da sensibilização da sociedade quanto aos problemas ambientais e suas possíveis soluções, a Educação Ambiental exerce um papel fundamental na promoção de mudança de hábitos. Não há mudança de percepção da realidade que não seja através da educação e das experimentações que ela nos traz. Uma nova consciência ambiental só pode ser alcançada através de pequenas e contínuas ações que mostrem que uma outra realidade é possível (GUENTHER, 2019; GUENTHER et al., 2019; GUENTHER et al., 2020).

Além disso, a Educação Ambiental não deve se limitar aos espaços de educação formal, como as escolas, colégios e universidades, ela deve estar presente "de forma articulada, em todos os níveis e modalidades do processo educativo", como atesta o artigo $2^{\circ}$ da Política Nacional da Educação Ambiental, a lei 9595/99 (BRASIL, 1999):

A Educação Ambiental é um componente essencial e permanente da educação nacional, devendo estar presente, de forma articulada, em todos os níveis e modalidades do processo educativo, em caráter formal e não-formal.

Em seu artigo 13, a PNEA define Educação Ambiental não formal (BRASIL, 1999):

Entendem-se por Educação Ambiental não-formal as ações e práticas educativas voltadas à sensibilização da coletividade sobre as questões ambientais e à sua organização e participação na defesa da qualidade do meio ambiente.

São nos espaços não formais de educação que a Educação Ambiental pode alcançar um público mais diverso em termos de faixa etária, condição social, formação, mas ao mesmo tempo consegue captar a atenção e sensibilizar este público por partilharem todos de interesses comuns. Os mutirões de limpeza de praias conseguem juntar todos aqueles que precisam desse ambiente em um único objetivo, mantê-lo limpo, agradável, saudável. Tanto para aqueles que utilizam a praia para o lazer quanto para aqueles que a utilizam para adquirir seu sustento, como pescadores, vendedores, instrutores 
de surf, kitesurf e outras modalidades aquáticas, jangadeiros, enfim, todos os trabalhadores que vivem desse ambiente, manter as praias e os mares limpos é fundamental. Ao verem pessoas se juntando para isso, mais pessoas se sentem estimuladas a colaborar, num grande círculo virtuoso.

Muitas iniciativas de limpeza de praias, ilhas e mares vem se desenvolvendo tanto em nível internacional, quanto nacional e local, todas com o mesmo objetivo de sensibilizar as pessoas em relação aos problemas causados pelos plásticos à vida marinha, à vida terrestre e à nossa saúde.

Em nível internacional destacamos 0 projeto "4 Ocean" (https://www.4ocean.com), que teve início em 2017 na Florida (EUA) e tem como principal ação a limpeza das praias e dos oceanos ao redor do mundo, o projeto "Bye Bye plastic bags" (http://www.byebyeplasticbags.org) com início em 2018 em Bali na Indonésia, tendo como principais ações a limpeza das praias, além de palestras nas escolas e elaboração de cartilhas para as crianças.

Em nível nacional, destacamos o projeto "Eco Surf" criado em 2000 em Itanhaém, na Baixada Santista, litoral norte de São Paulo (http://www.ecosurf.org.br) e o projeto "Route Brasil" (https://routebrasil.org)., criado em 2001 em Florianópolis - SC com diversas ações de limpeza de praias e Educação Ambiental.

Em nível local, trazemos nesse artigo a experiência do projeto "Xô Plástico", um projeto de Educação Ambiental não formal que vem desenvolvendo ações de limpeza de praias e manguezais com o objetivo de sensibilizar a população a respeito do consumo excessivo e do descarte incorreto dos resíduos, discutindo alternativas que minimizem esse impacto.

Com a era dos descartáveis, as pessoas tendem cada vez mais a utilizar esse tipo de material devido a sua praticidade, versatilidade e fácil manuseio. Mas esses materiais são, em sua maioria, descartados incorretamente, causando assim grandes impactos ao meio ambiente, que por sua vez atingem diretamente e indiretamente os mesmos que os causam. Este projeto surgiu então como uma forma de combater esse problema, trazendo ações de limpeza, que envolvem a coleta do lixo encontrado, diálogos a respeito da situação atual e de como podemos com simples atitudes mudar aos poucos nossos hábitos de consumo e descarte.

\section{Ações desenvolvidas pelo projeto Xô Plástico}

Desde a criação do projeto, em outubro de 2018 até a suspensão das atividades presenciais devido à pandemia da COVID-19 em março de 2020, foram realizadas 34 ações em praias e manguezais do estado de Pernambuco. A primeira ação aconteceu no dia 24 de novembro de 2018 na Praia do Pina, litoral de Pernambuco, onde foram recolhidos $33 \mathrm{~kg}$ de resíduos por uma equipe de 18 voluntários. Em outra ação realizada no manguezal urbano às 
margens do Rio Capibaribe, na Rua da Aurora, Recife, foram coletados $460 \mathrm{~kg}$ de resíduos por uma equipe de 62 voluntários (Figura 1). Todos os resíduos coletados nas ações do projeto são separados e destinados à EMLURB Autarquia de Manutenção e Limpeza Urbana da Cidade do Recife.

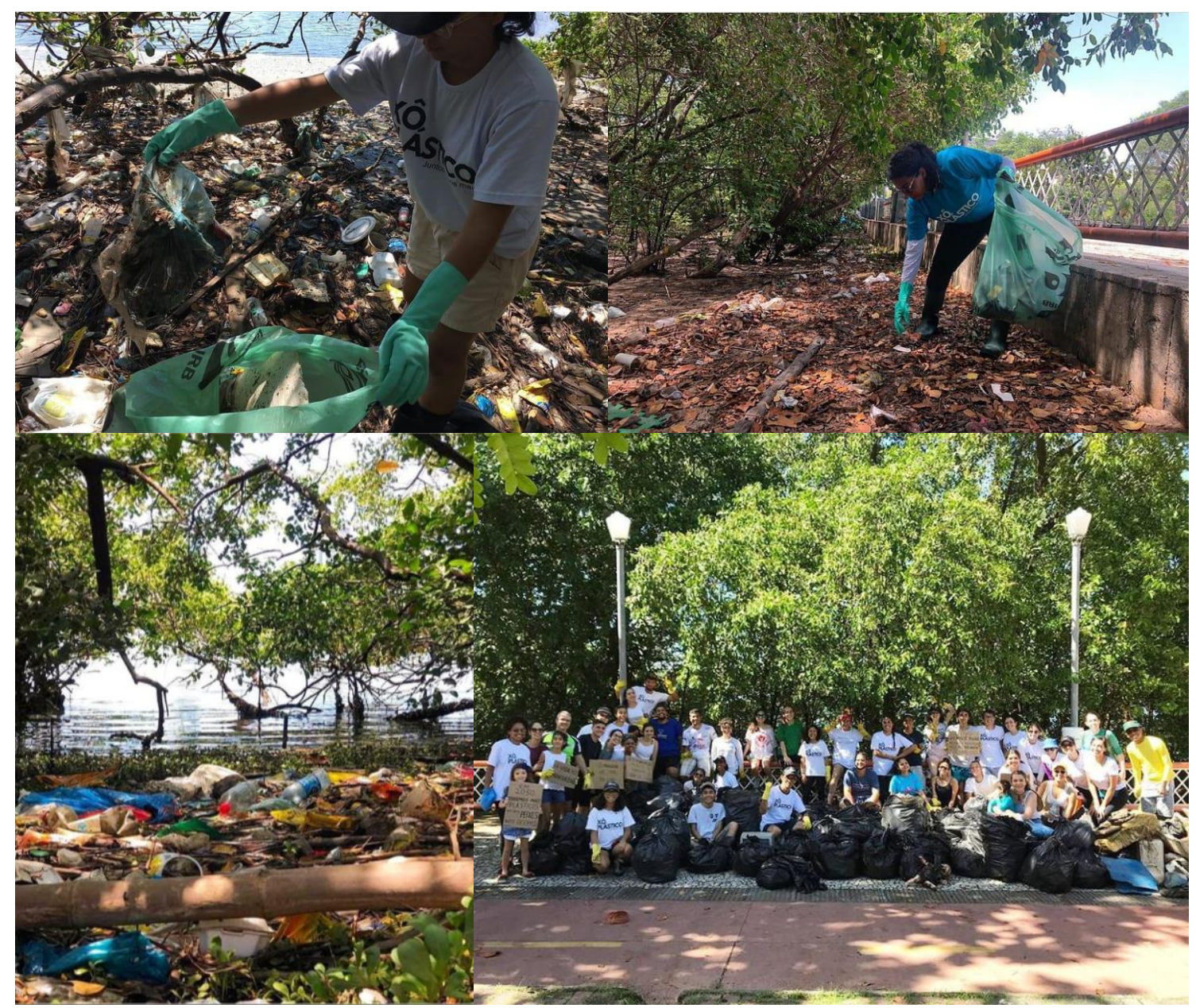

Figura 1: Ação de coleta de lixo no manguezal da rua da Aurora (Recife - PE).

Fonte: As autoras.

\section{A participação dos voluntários}

A convocação dos voluntários é feita através das redes sociais Instagram, Facebook e WhatsApp. A partir do perfil no Instagram (@xoplastico), o público tem acesso aos ideais e principais objetivos do projeto. As informações sobre as ações são compartilhadas, assim como o local, horário e equipamentos de proteção individual necessários. Ao final de cada ação, as imagens também são compartilhadas no perfil. Assim, mais pessoas vão entrando em contato para mais informações e passam a participar das ações futuras (Figura 2). 


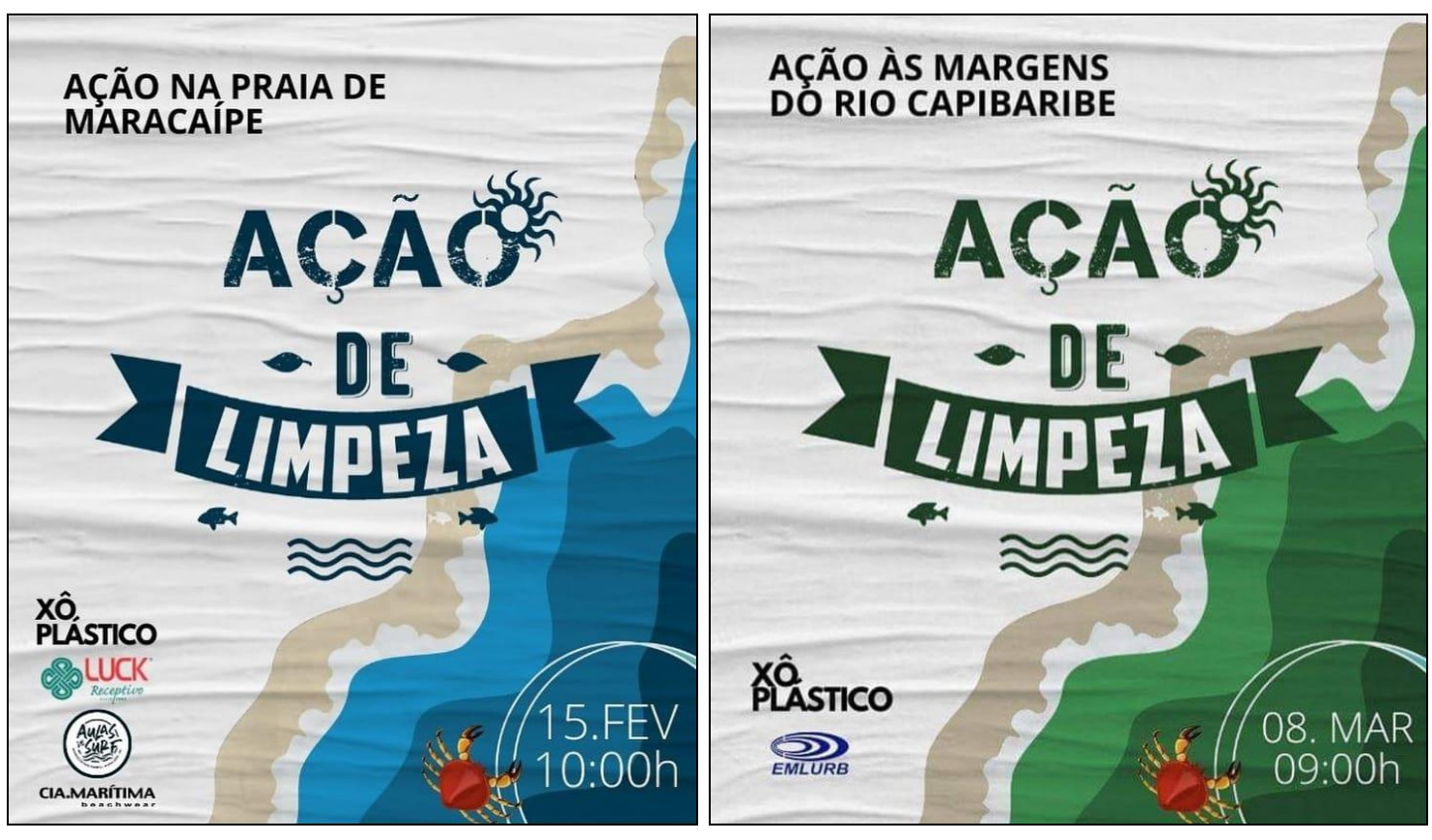

Figura 2: Convocação dos voluntários paras as ações de limpeza através das redes sociais.

Fonte: As autoras.

As ações de Educação Ambiental do projeto Xô Plástico têm o objetivo de sensibilizar o público sobre os impactos que os resíduos geram nos ambientes terrestres e marinhos. A metodologia de cada ação consiste em uma roda de conversa inicial com os voluntários onde são mostrados e explicados os impactos dos resíduos plásticos que se encontram no local da ação como a ingestão pelos animais, a fragmentação em pedaços menores (micro plásticos) a partir da ação da luz solar e da temperatura, o tempo de decomposição desse material e as substâncias contaminantes que são liberadas desses resíduos. Nesse momento também são apresentadas e discutidas alternativas para a redução do consumo de plástico, além das várias possibilidades de reutilização e reciclagem.

Após essa conversa a equipe realiza o mutirão de coleta, separando e acondicionando o material em sacos plásticos que ao final são pesados e destinados à companhia de limpeza pública da cidade. Ao final de cada ação um novo momento de conversa acontece com os voluntários para avaliar se os objetivos foram alcançados.

Desse modo, para compor o presente relato, foram entrevistados 58 voluntários que participaram das ações do projeto para saber quais foram suas motivações para participar dos mutiões de limpeza e quais foram os principais efeitos dessas ações sobre as eventuais mudanças nos seus hábitos cotidianos.

As entrevistas abrangeram questões gerais de identificação como gênero, idade, bairro e município de residência e escolaridade, e perguntas mais específicas sobre o projeto tais como: como o(a) voluntário(a) conheceu o 
projeto, de quais ações participou, o que o motivou a participar, se indicou algum amigo a participar de futuras ações, e se os hábitos de consumo mudaram após a participação nas ações.

Dos 58 entrevistados, sendo 37 mulheres (64\%), 19 homens (33\%) e 2 (3\%) que não declararam o gênero, a maioria (60,7\%) tinha idades entre 19 e 22 anos. Todos eram moradores do estado de Pernambuco, sendo a maioria residente no município de Recife (65,5\%), seguido dos residentes em Olinda $(12 \%)$ e Jaboatão dos Guararapes (5\%). Analisando a procedência dos voluntários por bairros, observamos uma grande diversidade na nossa amostra, com 48 bairros representados, sendo 22 do município de Recife.

A maior parte dos nossos entrevistados $(65,5 \%)$ estava cursando o Ensino Superior. Alguns (23\%) já tinham ensino superior completo, sendo 14\% com pós-graduação completa ou em andamento. Apesar das redes sociais terem um efeito importante na divulgação do projeto, a maioria dos entrevistados (72.4\%) conheceu o projeto por indicação dos amigos. $\mathrm{E}$ entre as redes sociais, o Instagram foi o que teve mais sucesso na divulgação (45\%).

Em relação à motivação a participar nas ações do projeto, a maioria participou por preocupação com o ambiente (91,4\%), sendo que muitos também relataram a indicação dos amigos (31\%) e a curiosidade $(22,4 \%)$ como fatores que o levaram a conhecer e participar dos mutirões. $E$ quando indagados sobre seus hábitos cotidianos, $67,2 \%$ relataram que a participação nas ações promoveu mudanças significativas e para $31 \%$ tais mudanças foram medianas. Apenas uma pessoa relatou não ter sentido nenhuma mudança em seus hábitos.

A partir desses resultados, percebemos que a maioria da equipe de voluntários foi composta por jovens estudantes de graduação levados a participar do projeto por já terem uma preocupação com o ambiente. Embora fosse um público já motivado a engajar-se a causas ambientais, a participação nas ações promoveu uma mudança de hábitos na imensa maioria dos entrevistados, o que indica que as ações atingiram seus objetivos.

A seguir destacamos alguns relatos dos voluntários sobre como a participação dessas ações afetaram seus hábitos do dia a dia:

"Eu já tinha uma preocupação sobre como nós seres humanos vínhamos modificando a natureza e como tudo isso prejudica a nossa existência, mas participando do Xô Plástico eu pude fazer a mudança acontecer, na prática. Os mutirões de limpeza na minha visão são mais que simplesmente catar plástico, é um aprendizado, de como precisamos mudar o sistema e se desculpar com a natureza."

"A visão de lixo mudou bastante, sendo muitas vezes objeto de reaproveitamento. O contato com o externo também mudou, uma vez que não existe jogar fora. Fazer compras significa automaticamente levar ecobags, sempre, e escolher produtos com menos embalagens possível." 
"Agora utilizo o mínimo de sacolas plásticas. Procuro comprar produtos sem muitas embalagens. Separo matérias que podem liberar substâncias tóxicas no ambiente e levo para reciclagem correta. Comecei a utilizar produtos $100 \%$ naturais. Antes de comprar algo, vejo se é realmente necessário."

"Passei a ter o hábito de recolher plástico todas as vezes em que vou na praia, recolher qualquer coisa que não deva fazer parte do meio ambiente. Também deixei de usar determinados produtos que encontramos poluindo a praia e outros ambientes, como: canudo plástico, palito de dente embalado em plástico e outros."

"Com as ações, passei a notar a importância de não consumir descartáveis, sobretudo. Além de perceber que sim, pessoas comuns, unidas por um objetivo maior, podem mudar o mundo"

"Ver como influência a poluição do ser humano causa no meio ambiente, trazendo diversos prejuízos para a fauna e a flora brasileira. Vendo de perto, faz com que a pessoa queria mudar seus hábitos para mais sustentáveis e poder ajudar ao máximo o planeta a se regenerar. Antes que seja tarde demais."

A partir desses relatos, é possível observar o alcance e a capacidade de mudança de hábitos dessas ações, que não se tratam apenas de um mutirão de coleta de resíduos e sim de atividades educativas e transformadoras. A Educação Ambiental através do processo conjunto e contínuo de reflexão e ação exerce um papel fundamental na sensibilização e conscientização do indivíduo que então se percebe cidadão, protagonista das mudanças que deseja para seu futuro.

\section{Dificuldades enfrentadas ao longo do desenvolvimento do projeto}

O projeto "Xô Plástico" enfrenta dificuldades desde a sua criação, pois a manutenção de um projeto como este tem um custo alto, seja para os materiais necessários para a limpeza, como saco de lixo, luvas, álcool em gel, seja para o lanche dos voluntários. Além disso, há a necessidade de uma cooperativa que possa buscar de forma gratuita os resíduos coletados para a reciclagem e para dar o destino correto aos resíduos orgânicos. Algumas praias mais distantes apresentam dificuldade de acesso, tanto para as organizadoras da ação quanto para os próprios voluntários. Manter os voluntários engajados e interessados em participar de todas as ações também têm sido um desafio, pois muitos participam de uma ação, elogiam, se mostram interessados, mas não voltam.

O projeto ainda não tem apoio financeiro para a realização das limpezas, por isso tem buscado parcerias efetivas com empresas. Nas primeiras ações os voluntários tinham que levar seus próprios equipamentos de proteção individual (EPI) como luvas e sacos de lixo, além de seus próprios 
lanches nas ações. Após a confecção e venda das camisas do movimento, a verba arrecadada ajudou muito a custear esse material. Algumas empresas, após conhecer os impactos positivos das ações, também começaram a doar materiais, apesar de ainda não ser suficiente.

\section{A importância da divulgação e o 'feedback' das redes sociais}

Todas as ações do projeto são divulgadas através das redes sociais Instagram, Facebook e WhatsApp. Essa divulgação é essencial para o conhecimento e comparecimento dos voluntários. Todas as ferramentas dos aplicativos são utilizadas a favor da propagação da informação, onde através dela mais pessoas são atraídas pelo convite e encorajadas a comparecerem às ações. Para manter o público engajado são realizadas postagens semanais sobre as notícias mais recentes relacionadas ao meio ambiente e seus impactos. Estratégias como respostas aos comentários nas publicações são feitas para manter os voluntários sempre perto e bem acolhidos.

Ferramentas do próprio aplicativo Instagram permite que dados de visualização do público sejam analisados. Uma delas é o alcance, que é uma métrica que estima o número de contas únicas que viram qualquer uma das publicações ou stories, sem contar repetições de usuário, nos últimos sete dias. Outra métrica utilizada é a de "impressões", onde estima-se o número total de vezes que as suas publicações e stories foram vistos, sem diferenciar se ele foi visualizado mais de uma vez pelo mesmo usuário, nos últimos 7 dias. Assim, conseguimos acompanhar a adesão do público, receber sugestões para a realização de novas ações e também compartilhar dicas sustentáveis que ajudem a preservar o meio ambiente.

\section{Conclusões}

Esse artigo demonstra o quanto o acúmulo de plástico no ambiente se tornou um problema crônico mundial, aparentemente sem solução, e o quanto as ações de Educação Ambiental são necessárias para promover mudanças de hábitos tão importantes para revertermos esse quadro. Os depoimentos dos voluntários do projeto "Xô Plástico" mostram o papel transformador dessas ações e a influência que estas podem exercer sobre os hábitos e atitudes dos cidadãos que delas participam.

Por outro lado, o investimento financeiro através de patrocínio e parcerias é fundamental para que ações como essa se ampliem, reunindo mais pessoas e abrangendo áreas mais extensas. A Educação Ambiental é um direito da sociedade e um dever do poder público, definido por lei. Esperamos, através desse relato, inspirar mais pessoas a agirem em suas comunidades, buscando parcerias e financiamento que viabilizem projetos semelhantes. Ações e reflexões locais são capazes de promover grandes mudanças em âmbito global. 
Agradecimentos: Agradecemos a todos os voluntários e apoiadores do projeto "Xô Plástico" pela participação nas ações e na pesquisa apresentada nesse artigo e à Prefeitura do Recife, através da Autarquia de Manutenção e Limpeza Urbana do Recife (EMLURB) e à agência de viagens LUCK de Recife, pelo apoio nas ações de limpeza das praias e dos mangues do estado de Pernambuco.

\section{Referências}

BRASIL. Lei n. 9.795, de 27 de abril de 1999. Dispõe sobre a Educação Ambiental, institui a Política Nacional de Educação Ambiental e dá outras providências. Brasília, DF, 1999. Disponível em: $<$ http://www.planalto.gov.br/ccivil 03/Leis/L9795.htm>.

CORTEZ, A.T.C. Aplicação de métodos e técnicas sustentáveis na gestão de resíduos sólidos. GeoGraphos. v. 7, n. 87 (4), p. 1-27, 2016.

DALY, N. For animals, plastic is turning the ocean into a minefield. National Geographic, 01 jun $2018 . \quad$ Disponível em: $<$ https://www.nationalgeographic.com/magazine/article/plastic-planet-animalswildlife-impact-waste-pollution>.

DIEZ, S.G. Referencias históricas y evolución de los plásticos. Revista Iberoamericana de Polímeros, v. 10, n. 1, p. 71-80, 2009.

DUNCAN, E.M. et al. A global review of marine turtle entanglement in anthropogenic debris: a baseline for further action. Endangered Species Research. v. 34, n. 36, p. 431-448, 2017.

EPHC - Environmental Protection and Heritage Council. Investigation of options to reduce the environmental impact of plastic bags. Melbourne: EPHC Australia, 2008. 207 p. Disponível em: $<$ http://www.nepc.gov.au/system/files/resources/0c513e54-d968-ac04-758b3b7613af0d07/files/ps-pbags-decision-ris-options-reduce-impacts-inclappendicescd-200805.pdf>.

FAO - Food and Agriculture Organization of the United Nations. The state of world fisheries and aquaculture: opportunities and challenges. Roma: FAO, 2014. 243p. Disponível em: <http://www.fao.org/3/i3720e/i3720e.pdf>.

GEYER, R.; JAMBECK, J.R.; LAW, K.L. Production, use, and fate of all plastics ever made. Science Advances. v. 3, n. 7, e1700782, 2017.

GIBBENS, S. Chemicals from plastics, cosmetics found in wild dolphins. National Geographic, 07 set 2018: Disponível em: $<$ https://www.nationalgeographic.com/animals/article/news-dolphins-plasticchemical-traces-found $>$.

GUENTHER, M. Educação Ambiental no ensino superior: um relato de experiências. Recife: EDUPE, 2019. 81p. 
GUENTHER, M. et al. Implementação de composteiras e hortas orgânicas em escolas: sustentabilidade e alimentação saudável. Revista Brasileira de Educação Ambiental. v. 15 n. 7, p. 391-409, 2020.

GUENTHER, M.; FERREIRA, M.L.S; SANTANA, A.D.S. Brincando com os resíduos: reutilização e reciclagem na Educação Infantil. Revista Brasileira de Educação Ambiental. v. 14 n. 1, p. 101-110, 2019.

HARDING, S. Marine debris: understanding, preventing and mitigating the significant adverse impacts on marine and coastal biodiversity. Technical Series No.83. Montreal: Secretariat of the Convention on Biological Diversity, Montreal, 2016. 78 p.

HARRIS, P.T. et al. Exposure of coastal environments to river-sourced plastic pollution. Science of The Total Environment, v 769. p. 145222, 2021.

JAMBECK, J.R. et al. Plastic waste inputs from land into the ocean. Science. v. 347, n. 6223, p. 768-771, 2015.

KURNIAWAN, S. B. et al. Current state of marine plastic pollution and its technology for more eminent evidence: a review. Journal of Cleaner Production, v 278, p. 123537, 2021.

LEAHY, S. Seabirds that eat plastic and live have major health problems. National Geographic, 02 ago 2019. Disponível em: https://www.nationalgeographic.com/environment/article/seabirds-eat-plasticmajor-health-effects

LEBRETON et al. Evidence that the Great Pacific Garbage Patch is rapidly accumulating plastic. Scientific Reports, v. 8, n. 4666, 2018. DOI: 10.1038/s41598-018-22939-w

LI. W.C.; TSE. H.F.; FOK L. Plastic waste in the marine environment: a review of sources, occurrence and effects. Science of The Total Environment, v. 566-567, p. 333-349, 2016.

LIMA, E.G.; OKIMOTO, M.L.L.R. Revisão da aplicação de produtos biopolímeros obtidos pela reciclagem de plásticos em design. Revista Iberoamericana de Polímeros, v. 10, n. 5, p. 244-259, 2009.

MIRANDA, J.G. 2010. 29 f. Era do plástico. Monografia (Curso de Graduação em Comunicação Social - Publicidade e Propaganda), Curso de Graduação em Comunicação Social, Faculdades Integradas Hélio Alonso.

MOORE, C.J.; MOORE, S.L.; LEECASTER, M.K.; WEISBERG, S.B. A comparison of plastic and plankton in the North Pacific Central Gyre. Marine Pollution Bulletin, v. 42, p. 1297-1300, 2001.

NATGEO - National Geographic. Great Pacific Garbage Patch. Washington: NATGEO, $2019 . \quad$ Disponível em: $<$ https://www.nationalgeographic.org/encyclopedia/great-pacific-garbagepatch/>. 
PARKER, L. A Grande llha de Lixo do Pacífico não é aquilo que se pensa. National Geographic, 09 abr 2018. Disponível em: $<$ https://www.natgeo.pt/meio-ambiente/2018/04/grande-ilha-de-lixo-do-pacificonao-e-aquilo-que-se-pensa>.

PIATTI, T.M.; RODRIGUES, R.A.F. Plásticos: características, usos, produção e impactos ambientais. Série Conversando sobre ciências em Alagoas. Maceió: EDUFAL, 2005. 51p.

PINTO, J. C. et al. Impactos ambientais causados pelos plásticos: uma discussão abrangente sobre os mitos e os dados científicos. $2^{\underline{a}}$ ed. Rio de Janeiro: E-papers Serviços Editoriais Ltda. 2012. 364 p. Disponível em: $<$ http://www.e-papers.com.br/produtos.asp?codigo produto=2262 >.

QUIRINO, C.A.S; SANTOS, V.M.L. Ações sustentáveis e suas implicações no trabalho: uma análise acerca do uso de copos descartáveis no colegiado de engenharia elétrica na UNIVASF. Revista Gestão e Sustentabilidade Ambiental. v. 9, n. 3, p. 3-28, 2020.

RODRIGUES, C.R.F. 2020. 106 f. Elaboração de planos de ações visando implantar atividades de sustentabilidade ambiental dentro de uma instituição de ensino superior localizada no interior de São Paulo. Dissertação (Mestrado em Tecnologia Ambiental) - Curso de Pós Graduação em Tecnologia Ambiental, Universidade de Ribeirão Preto, UNAERP.

SANTOS, A.S.F.; FREIRE, F.H. O.; COSTA, B.L.N.; MANRICH, S. Sacolas plásticas: destinações sustentáveis e alternativas de substituição. Polímeros, v. 22, n. 3, p. 228-237, 2012.

SOBRAL, M.F.F; SOBRAL, A.I.G.P. Casos de dengue e coleta de lixo urbano: um estudo na Cidade do Recife, Brasil. Ciência e saúde coletiva. v. 24, n. 3, p. 1075-1082, 2019. DOI: 10.1590/1413-81232018243.10702017

UNEP - United Nations Environment Programme. Marine plastic debris and microplastics: global lessons and research to inspire action and guide policy change. Nairobi: UNEP, 2016. 274p.

WIT, W. et al. Solucionar a poluição plástica: transparência e responsabilização. Gland: WWF, 2019. 50p. 